\section{A case report of Pancreatico Pleural Fistula presenting as recurrent right pleural effusion}

\author{
Harveen Kaur ${ }^{1 *}$, Dilbag Singh ${ }^{1}$, NC Kajal ${ }^{2}$ and \\ Deepak Garg'
}

'Junior Resident, Department of Pulmonary Medicine, Government Medical College, Amritsar, Punjab, India

${ }^{2}$ Professor, Department of Pulmonary Medicine, Government Medical College, Amritsar, Punjab, India
Received: 12 July, 2021

Accepted: 22 July, 2021

Published: 23 July, 2021

*Corresponding author: Harveen Kaur, Junior Resident, Department of Pulmonary Medicine, Government Medical College, Amritsar, Punjab, India, Tel: +919465958100; Email: hk_94basra@ymail.com, veenu. basra@gmail.com

ORCID: https://orcid.org/0000-0002-9380-3173

Keywords: Pancreaticopleural Fistula (PPF); Pleural effusion; Chronic pancreatitis; Chest X-ray; Thoracocentesis; Contrast Enhanced Computed Tomography (CECT) Chest; CECT abdomen

https://www.peertechzpublications.com

\section{Check for updates}

\begin{abstract}
Pancreaticopleural Fistula (PPF), is an uncommon and serious complication of chronic pancreatitis. PPF needs to be included in the differential diagnosis of recurrent and large pleural effusions especially in middle-aged men with a history of alcohol consumption. The diagnosis requires high index of suspicion, since the patients present typically with the pulmonary symptoms related to pleural effusion rather than pancreatitis. We present a case of a middle-aged male with massive recurrent right-sided pleural effusion, secondary to PPF due to chronic pancreatitis.
\end{abstract}

\section{Introduction}

Pancreaticopleural Fistula (PPF) is a rare complication seen approximately in $0.4 \%$ of patients with chronic pancreatitis. There occurs an abnormal communication, known as fistula, between the pancreatic duct and the pleural space, due to the leakage or rupture of a pancreatic pseudocyst or disruption of pancreatic Duct (PD). The drainage of pancreatic secretions into the pleura causes amylase rich pleural effusion subsequently in these patients [1]. In comparison to the pleural effusions seen in pancreatitis that are clinically insignificant, a PPF produces recurrent, large volume effusions. Owing to its low incidence, it is rarely considered as a cause of pleural effusion.

Patients present with typical symptoms which are mainly pulmonary, rather than abdominal, leading to delayed diagnosis. The presenting findings being large, recurrent pleural effusion in majority of the cases [2].

Thediagnosisin suchcases is difficult, but theclinicalfindings aided with amylase-rich pleural fluids and demonstration of fistula tract on imaging like Computed Tomography (CT) or Magnetic Resonance Cholangiopancreatography (MRCP) helps to establish the cause. CT is an easily accessible method and shows both the thoracic and abdominal findings non-invasively. It is useful for imaging findings of chronic pancreatitis and can clarify the site of fistulisation and give details of anatomical relations of the fistula with other organs [3].

We present a case of a 37-years-old male patient suffering from chronic alcoholism, who presented with a recurrent right pleural effusion due to a PPF, diagnosed by clinical findings, pleural fluid analysis and imaging, and who was subsequently managed with conservative medical management.

\section{Case report}

A 37-years-old male presented with complaint of abdominal pain and shortness of breath. Abdominal pain was in the epigastric area, sharp, radiating to the back, associated with nausea. He was a chronic alcoholic for the past 10 years. He was non-diabetic, with no previous history of tuberculosis and no history of any cardiac illness.

On examination, he was alert, oriented with the vitals heart rate of 84 beats per minute, blood pressure $122 / 76 \mathrm{mmHg}$, 
respiratory rate of 18 breaths per minute, temperature $36.4^{\circ} \mathrm{C}$, oxygen saturation $94 \%$ on room air. On percussion, there was stony dull note on the right side of chest. On auscultation, decreased breath sounds noted on the right hemithorax. Cardiac auscultation revealed regular rate and rhythm with normal S1 and S2. There was epigastric tenderness on examination of the abdomen. Examination of the other systems was unremarkable.

Initial laboratory evaluations were: Haemoglobin $11.0 \mathrm{~g} /$ dL (normal range: 13.5-17.5), WBC count 14,900/l (normal range: 4500-11,000), serum amylase $989 \mathrm{U} / \mathrm{L}$ (normal range: 40-140), serum lipase $721 \mathrm{U} / \mathrm{L}$ (normal range: 10-140), BUN $20 \mathrm{mg} / \mathrm{dL}$ (normal range: 7-20), serum creatinine $0.94 \mathrm{mg} / \mathrm{dL}$ (normal range: 0.74-1.35), AST $32 \mathrm{U} / \mathrm{L}$ (normal range: 0-35), ALT 28 U/L (normal range: 7-56), serum ALP 48 U/L (normal range: $20-140$ ), and total bilirubin $0.7 \mathrm{mg} / \mathrm{dL}$ (normal range: 0.1-1.2). He tested negative for HIV, hepatitis B and hepatitis C. Mantoux test was non-reactive.

Chest X-ray showed massive right sided pleural effusion (Figure 1). Ultrasonography (USG) Chest showed massive amount of free fluid in the right pleural cavity with internal echoes and septations. Upon thoracocentesis, $980 \mathrm{~mL}$ of brownish colour pleural fluid aspirated (Figure 2), which was exudative with significantly elevated amylase and lipase (pleural fluid amylase $2198 \mathrm{U} / \mathrm{L}$, lipase $3654 \mathrm{U} / \mathrm{L}, \mathrm{pH} 7.4$, total proteins $1.6 \mathrm{~g} / \mathrm{dL}$, LDH $54 \mathrm{U} / \mathrm{L}$, serum LDH $240 \mathrm{U} / \mathrm{L}$, serum total proteins $5.5 \mathrm{~g} / \mathrm{dL}$ ), raising the suspicion of PPF formation secondary to chronic pancreatitis. Repeat chest X-rays revealed re-accumulation of the pleural fluid. Pleural fluid cultures were negative for aerobic, anaerobic agents and fungi. Pleural fluid for Cartridge Based Nucleic Acid Amplification Test (CBNAAT) tested negative for Mycobacterium tuberculosis and the cytological evaluation of fluid did not reveal malignant cells.

CECT (Contrast Enhanced Computed Tomography) Chest revealed right-sided heterogeneous large pleural effusion with underlying partial lung collapse. CECT Abdomen (Figure 3) showed a $3.3 \mathrm{~cm}$ peripancreatic peripherally enhancing fluid collection communicating with the main pancreatic duct, with walled of necrosis and evidence of chronic pancreatitis, suggesting formation of PPF.

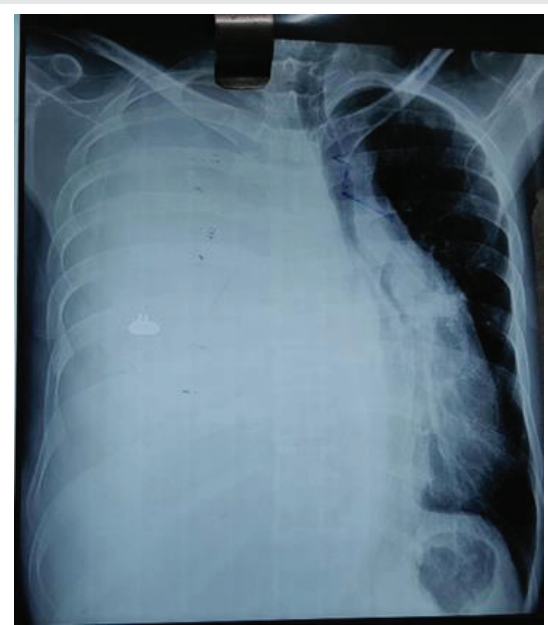

Figure 1: Chest $X$-ray shows massive right sided pleural effusion

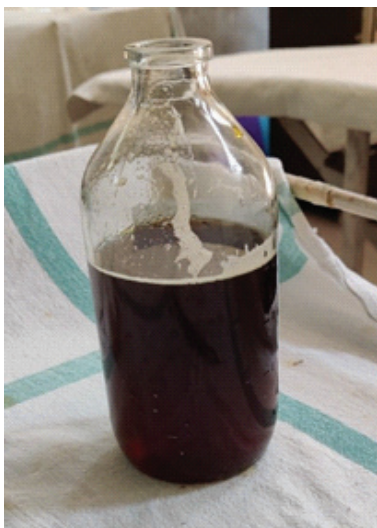

Figure 2: Brown coloured pleural fluid aspirated upon thoracocentesis.

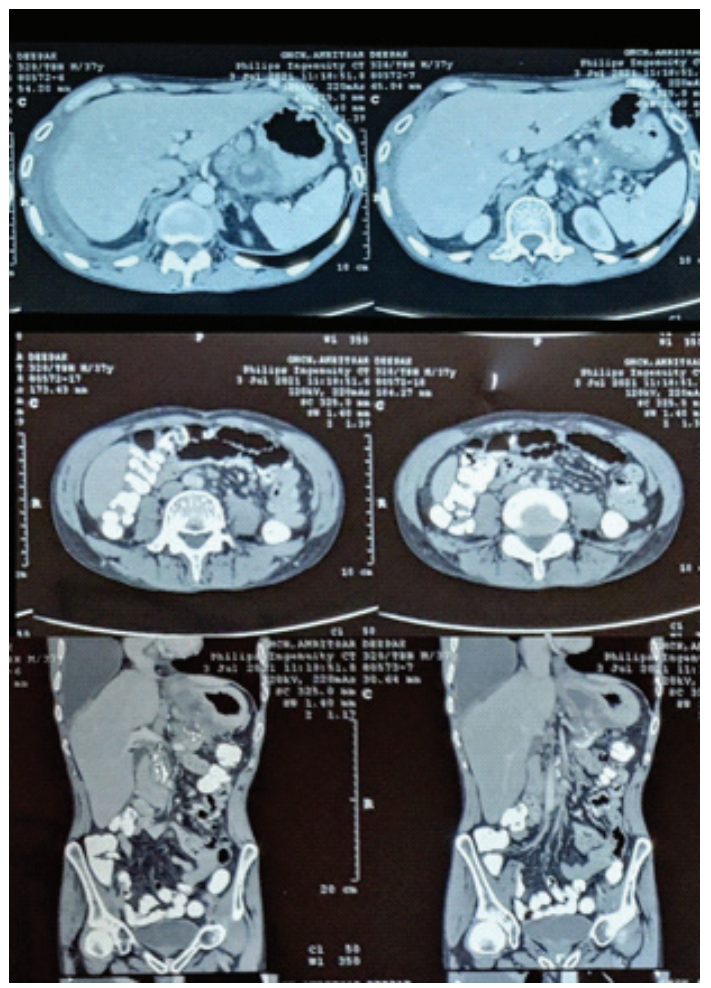

Figure 3: CECT Abdomen shows atrophied pancreas with multiple foci of calcification and peripancreatic, thick-walled collection with extensions and abdominal lymphadenopathy, along with prominent MPD communicating with the collection.

As per the protocol for initial management of PPF and patient's denial for invasive management options, he was started on octreotide, along with appropriate antibiotic treatment, total parenteral nutrition and drainage of the pleural effusion. Throughout this hospitalization, his symptoms of shortness of breath, abdominal pain and nausea showed improvement. A follow-up CT scan done after 3 weeks of treatment completion, revealed a decrease in the size of the fistula and the peripancreatic collection along with the reduction in the amount of the pleural fluid.

\section{Discussion}

Pancreaticopleural Fistula (PPF) formation is rare, occurs in about $1 \%$ patients with acute pancreatitis and in $0.4 \%$ patients with chronic pancreatitis [1]. It is an abnormal collection 
of pancreatic secretions contained within a non-epithelial wall, primarily composed of granular and fibrous tissue [4]. The various etiologies for its formation include: alcoholrelated chronic pancreatitis (leading cause), pancreatitis due to gallstones, idiopathic pancreatitis, trauma or congenital pancreatic duct anomalies [5]. PPF formation due to the rupture of posterior pancreatic pseudocyst causes the pancreatic secretions to ascend to the pleural space due to abnormal connection of the pancreatic duct to the pleural space. These cases of PPF-related pleural effusion have to be differentiated from the reactive pleural effusion occurring with pancreatitis, which usually is left-sided and self-limiting; however, right and bilateral effusions can also occur [6].

The typical presentation of PPF is a middle-aged male, with chronic pancreatitis secondary to alcoholism. Patient presents with recurrent pleural effusion, which rapidly reaccumulates and is resistant to thoracentesis. In such cases, pleural effusion is more common on left side $(42 \%-67 \%)$, though it can also be right sided $(19 \%-40 \%)$ or bilateral $(14 \%-17 \%)$. Patient reports with pulmonary symptoms, shortness of breath being the most common presenting complaint in $65 \%-76 \%$ and abdominal symptoms reported in $24 \%$ of these cases $[7,8]$.

History and physical examination are non-specific for PPF and thus, further evaluation with imaging and laboratory work-up is needed. The establishment of diagnosis is via thoracocentesis with subsequent pleural fluid analysis demonstrating exudative effusion with significantly elevated amylase levels [1]. In the cases with moderately elevated amylase levels, imaging findings are helpful in diagnosis. Following this, the next step is confirmation of the presence of the fistula, for which most sensitive imaging modality is MRCP, followed by Endoscopic Retrograde Cholangiopancreatography (ERCP) and CT scan [9]. CT has the advantage of being noninvasive and the capability of providing three-dimensional images. In this case, CECT chest and abdomen was performed which revealed the chronic pancreatitis changes (parenchymal changes, dilatation of the duct and fluid collection), along with abnormal duct communication with the collection suggestive of PPF.

The treatment of PPF requires multidisciplinary approach, comprising of pulmonary, gastroenterology and general surgery teams. Management options can be medical, endoscopic, or surgical depending on the individual case [10]. Endoscopic management with ERCP stenting to the pancreatic duct is a successful option. If no strictures are found in the pancreatic duct on MRCP, such patients can be managed medically. Surgical management is the last resort when medical and ERCP treatment fails. In the case discussed above, patient was managed medically with octreotide to reduce pancreatic secretions accompanied by total parenteral nutrition and drainage of pleural effusion in that period. The patient improved clinically though the course of the medical management.

\section{Conclusion}

Pancreaticopleural Fistula (PPF) is a serious complication of acute or chronic pancreatitis. The diagnosis of PPF requires a high index of suspicion along with a compatible clinical picture. Demonstration of pleural fluid rich in amylase is the key diagnostic indicator aided with the radiological demonstration of the fistula. Multidisciplinary approach is needed for case dependent management, which can be medical, endoscopic or surgical.

\section{Declaration of patient consent}

The authors certify that they have obtained all appropriate patient consent forms. In the form the patient(s) has/have given his/her/their consent for his/her/their images and other clinical information to be reported in the journal. The patients understand that their names and initials will not be published and due efforts will be made to conceal their identity, but anonymity cannot be guaranteed.

\section{References}

1. Tay CM, Change SK (2013) Diagnosis and management of pancreaticopleural fistula. Singapore Medical J 54: 190-194. Link: https://bit.ly/3wUNc1u

2. Duncan ND, Ramphal PS, Dundas SE, Gandreti NK, Robinson-Bridgewater LA, et al. (2006) Pancreaticopleural fistula: a rare thoracic complication of pancreatic duct disruption. J Pediatr Surg 41: 580-582. Link: https://bit.ly/3BtxEoQ

3. Burgess NA, Moore HE, Williams JO, Lewis MH (1992) A review of pancreaticopleural fistula in pancreatitis and its management. HPB Surg 2013: 79-86. Link: https://bit.ly/3BwmxLE

4. Mihai C, Floria M, Vulpoi R, Nichita L, Cijevschi Prelipcean C, et al. (2018) Pancreatico-pleural fistula - from diagnosis to management. A case report. J Gastrointestin Liver Dis 27: 465-469. Link: https://bit.ly/36UAfdf

5. Francisco E, Mendes M, Vale S, Ferreira J (2019) Pancreaticopleural fistula: an unusual complication of pancreatitis. BMJ Case Rep 2015: bcr2014208814 Link: https://bit.ly/2UEVMEe

6. Tauseef A, Nandakumar S, Vu L, Chimpiri AR, Tierney WM (2009) Pancreaticopleural fistula. Pancreas 38: e26- e31. Link: https://bit.ly/3BsXEAX

7. Hirosawa T, Shimizu T, Isegawa T, Tanabe M (2016) Left pleural effusion caused by pancreaticopleural fistula with a pancreatic pseudocyst. BMJ Case Rep 2016: bcr2016217175. Link: https://bit.ly/3eKUfU5

8. Altasan T, Aljehani Y, Almalki A, Algamdi S, Talag A, et al. (2013) Pancreaticopleural fistula: an overlooked entity. Asian Cardiovasc Thorac Ann 22: 98-101. Link: https://bit.ly/3zrbrpp

9. Singh S, Yakubov M, Arya M (2018) The unusual case of dyspnea: a pancreaticopleural fistula. Clin Case Rep 6: 1020-1022. Link: https://bit.ly/3xWJG89

10. Chan EE, Shelat VG (2016) Pancreaticopleural fistula causing massive righ hydrothorax and respiratory failure. Case Rep Surg 2016: 8294056. Link: https://bit.ly/3izvKKK

Copyright: @ $2021 \mathrm{Kaur} \mathrm{H}$, et al. This is an open-access article distributed under the terms of the Creative Commons Attribution License, which permits unrestricted use, distribution, and reproduction in any medium, provided the original author and source are credited.

Citation: Kaur H, Singh D, Kajal NC, Garg D (2021) A case report of Pancreatico Pleural Fistula presenting as recurrent right pleural effusion. Arch Pulmonol Respir 